Review

\title{
Metastatic epidural spinal cord compression: current concepts and treatment
}

\author{
Robert Grant, ${ }^{1}$ Stephen M. Papadopoulos, ${ }^{3}$ Howard M. Sandler ${ }^{4}$ and Harry S. Greenberg ${ }^{2,3}$ \\ Department of ${ }^{\prime}$ Clinical Neurosciences-Neurology Unit, ${ }^{2}$ Western General Hospital, Edinburgh, Scotland, \\ UK; Departments of ${ }^{2}$ Neurology, ${ }^{3}$ Surgery-Section of Neurosurgery and ${ }^{4}$ Radiation Oncology, University of \\ Michigan, Ann Arbor, Michigan 48109, USA
}

Key words: cancer, emergency, epidural spinal cord compression, metastatic

\section{Summary}

Metastatic epidural spinal cord compression (MESCC) is a medical emergency complicating the course of $5-10 \%$ of patients with cancer [1]. When diagnosis and treatment is early with the patient ambulatory prognosis for continued ambulation is good [2]. If the patient is nonambulatory or paraplegic, prognosis for meaningful recovery of motor and bladder function is markedly decreased. In the last decade, significant advances in the understanding, management and treatment of metastatic epidural spinal cord compression have occurred.

Recent pathophysiological and pharmacological animals studies have afforded insights into disease mechanisms [3-9]. The audit of standard methods of investigation and magnetic resonance imaging have resulted in revision of guidelines for patient evaluation [10-17]. Finally, new surgical philosophies and technical advances have generated interest and controversy [18-25]. With improved clinical awareness, new imaging modalities will help us diagnose epidural spinal cord compression earlier and institute appropriate treatment.

\section{Introduction}

Metastatic epidural spinal cord compression (MESCC) will be defined as compression of the spinal cord or cauda equina nerve roots from a lesion outside the spinal dura. It is the initial manifestation of malignancy in half of cases diagnosed in a general hospital [26], but less than $8 \%$ diagnosed in cancer centers [2]. The most common tumors causing epidural compression are breast, lung, prostate, lymphoma, sarcoma, and kidney, accounting for over $70 \%$ of cases $[2,26-30]$.

In this paper, we review and summarize current concepts regarding the management of MESCC based on recent diagnostic advances and technical surgical developments. The review is based on our experience and critical appraisal of recent articles or seminal papers on metastatic epidural spinal cord compression. We discuss the pros and cons of diagnostic and treatment strategies to reduce the degree of uncertainty in selecting the appropriate modality for each clinical situation.

\section{Pathogenesis and pathophysiology}

The epidural space is a true space which lies between spinal cord dura and the bony spinal canal. It contains fat, connective tissue and a rich paravertebral venous plexus which drains the vertebrae and intervertebral spaces. The most common mechanism of metastatic epidural spinal cord compression is thought to be by hematogenous arterial spread to bone marrow, which results in vertebral body collapse and formation of an anterior epidural mass. A second mechanism is spread by direct in- 
vasion of tumor through the intervertebral foramina from a paravertebral source. This occurs in $75 \%$ of patients wiht epidural spinal cord compression due to lymphoma, and $15 \%$ of patients with metastatic epidural spinal cord compression from other solid tumors [31-33].

Although unproven, another probable mechanism of metastatic epidural spinal cord compression is by retrograde venous spread from the primary site via Batson's paravertebral plexus. If tumor cells are injected into the femoral vein, when intra-abdominal pressure is normal, metastases develop in the lungs, and when intra-abdominal pressure is increased, epidural metastases without vertebral involvement are produced [34]. In humans, it is rare to find metastatic epidural spinal cord compression without bony involvement or direct spread through the bony foramina.

Animal models have been used to demonstrate morphological features of cord damage and subsequent recovery $[35,36]$. Following 3 hours of cord compression in cats, selective demyelination without axonal disruption evolves over the subsequent 21 hours and continues for 1 week. Most demyelinated fibres show evidence of remyelination by one month [36]. If compression is produced slowly over a 48 hour period and maintained for 7 days, it is still possible to get recovery of paralysis, suggesting that demyelination is a more important factor than cord ischemia. With more prolonged compression there was cord ischemia and irreversible neurological changes. If tumor cells are injected into the epidural space in rats, one of the earliest features of metastatic epidural spinal cord compression is breakdown of the blood-spinal cord barrier with vasogenic edema [37]. Administration of steroids decreases the vasogenic edema and produces objective improvement in weakness [38].

At autopsy, in humans with metastatic epidural spinal cord compression, there is vascular congestion, hemorrhage and edema at the site of cord compression suggesting that venous occlusion is an important factor in the pathogenesis of cord damage.

\section{Topographical localization}

Eighty-four to ninty-four percent of patients with MESCC have an abnormal plain $x$-ray at the time of presentation $[26,27]$. Over $30 \%$ of patients will have $x$-ray evidence of multiple sites of vertebral involvement and if plain $x$-rays, tomography and surgical findings are combined, as many as $86 \%$ may have more than one vertebra involved [27, 29]. Multiple vertebral involvement is particularly common in breast and prostatic carcinoma. Metastatic epidural spinal cord compression most commonly occurs at the site of vertebral involvement on plain $\mathrm{x}$ ray, especially where there is evidence of vertebral collapse. The primary compression of the spinal cord from metastatic deposits occurs in the thoracic region of approximately $70 \%$ of patients, the lumbosacral spine in $20 \%$ and the cervical spine in $10 \%$ of patients $[2,26,32]$. Multiple sites of metastatic epidural spinal cord compression occur in $17-30 \%$ of all patients [39]. This is particularly common in breast cancer and is uncommon in lung cancer [26].

In a review of 600 cases of spinal cord or nerve root compression, vertebral metastases occurred in 563 patients [27]. The vertebral body was involved in $45 \%$ of these patients, the posterior arch in $41 \%$ and the entire vertebra in the remaining $14 \%$ of patients. Epidural lesions without vertebral involvement occurred in 30 patients and intradural lesions in 7 patients. The location within the vertebra of metastatic involvement is important for the surgical treatment of epidural spinal cord compression but is not a good indicator of the primary site of neoplasm [33]. Epidural metastases usually do not invade the dura. Posterior extradural tumor is easily accessible by laminectomy, but anterior extradural disease may require an anterior cervical, transthoracic or transabdominal approach.

\section{History and examination}

The median age at diagnosis of metastatic epidural spinal cord compression has varied from 53 to 63 years with sex differences reflecting the primary neoplasm e.g. breast and prostate [2, 26-30].

Back pain is the initial complaint in up to $96 \%$ of 
patients with epidural spinal cord compression [2] Pain may precede neurological symptoms by days to 3 or more years [1]. It is very unusual for patients with metastatic epidural spinal cord compression to present without pain [28], but cord compression from lung or renal metastases and lymphoma do so more frequently $[1,26]$. The median duration of pain before development of neurological signs has varied from 7 to 23 weeks $[2,26]$. Duration of pain is probably related to tumor growth rate, being shortest for highly malignant tumors such as lung and kidney and longest for more typically less malignant tumors such as breast and prostate carcinoma. The majority of patients have local pain, secondary to stretching of the pain sensitive cortical bone and periosteum. Local pain is usually constant, relentlessly progressive and exacerbated by coughing, sneezing, straining or exercise $[1,2]$. The worsening of pain on recumbency is the most distinctive feature of the pain of metastatic epidural spinal cord compression and differentiates it from disc disease $[1,2]$. Radicular pain is present in $90 \%$ of patients with lumbosacral, $79 \%$ of cervical and $55 \%$ of patients with thoracic metastatic epidural spinal cord compression [2]. It is frequently bilateral in the thoracic area and unilateral or bilateral in the lumbosacral and cervical areas. Radicular pain is an important localizing sign [2].

Weakness is present in about $80 \%$ of patients with metastatic epidural spinal cord compression at presentation [2]. Fifty percent of patients are ambulatory, $35 \%$ are paraparetic and $15 \%$ are paraplegic at the time of diagnosis [2]. Once weakness is present, progression is often rapid and urgent investigation and treatment is crucial $[2,26]$. Thirty percent of patients with weakness become paraplegic within one week [1]. Rate of progression of weakness is dependent on the tumor growth rate [1]. Weakness is usually bilateral and symmetrical $(87 \%)$ [2]. The degree of weakness and ability to ambulate at the time of diagnosis are important clinical predictors of outcome [2, 26-29].

Bladder and bowel symptoms are also frequently present at the time of diagnosis $(57 \%)$ and can take the form of frequency, urinary retention or incontinence [2]. Autonomic disturbance is a bad prognostic sign as it implies bilateral cord or root damage and is usually associated with moderate to severe weakness [2]. Objective sensory disturbance is found in $78 \%$ of patients at the time of diagnosis [2]. The severity of sensory loss almost always mirror the severity of motor weakness $[1,40]$.

Care should be taken to examine lymph nodes, breasts, lungs, kidneys and perform a rectal exam [40]. Limited straight leg raising usually points to an epidural or intradural extramedullary lesion causing root compression, while segmental pain and sacral sparing suggests intramedullary disease [40]. Spinal cord, conus medullaris, cauda equina, or peripheral nerve lesions can produce a flaccid areflexic paralysis $[1,40]$. Concurrent cerebral symptoms or signs favor performance of MRI where there is no risk of neurologic deterioration [41]. If there are two spinal levels involved clinically or on an x-ray, then both sites must be clearly imaged [2].

\section{Differential diagnosis}

If clinical outcome is to be improved, it is important to identify patients with metastatic epidural spinal cord compression early in their illness and start treatment as soon as possible $[26,28,41]$. Approximately $50 \%$ of adult patients presenting with an acute transverse myelopathy will be diagnosed as having metastatic epidural spinal cord compression [42]. In $47 \%$ of patients who develop metastatic epidural spinal cord compression, it is the initial presentation of their malignancy, and of these almost half will have lung carcinoma identified $[2,27]$.

However, less than $50 \%$ of patients with malignancy, considered clinically to have metastatic epidural spinal cord compression, will have this diagnosis confirmed by myelography [43]. Myelography in cancer patients with back pain and myelopathy is normal in $23 \%$ of patients, and with back pain and radiculopathy is normal in $37 \%$ of patients [44].

A history of previous radiation therapy, trauma, vascular or disc disease or infection is important. Patients taking anticoagulants have an increased risk of subdural hematoma [45]. Chemotherapy increases the risk of infections and hemorrhage [46, 47]. Patients receiving chronic steroids may develop cord compression from epidural fat [48]. 
The differentiation between epidural abscess and metastasis is often difficult [40]. Epidural abscess is more frequently posteriorly situated and will often cover multiple vertebral body segments [49]. If there is vertebral collapse due to an infective cause, the disc space is frequently destroyed while metastatic vertebral disease usually spares the disc space $[49,50]$. Epidural abscess may be associated with increased systemic white blood cell count, fever or cerebrospinal fluid pleocytosis, but as the dura is an effective barrier, the cerebrospinal fluid may be normal. Blood cultures yield the correct organism more often $[49,50]$.

Arteriovenous malformations can produce myelopathy as a result of direct pressure or following hemorrhage. In the majority of cases the arteriovenous malformation is at the thoraco-lumbar junction, either extradural or intradural, while in approximately $10 \%$ the arteriovenous malformation arises from the anterior spinal artery and is intramedullary in the cervical cord [40]. They may be identified by their 'snake like' appearance on myelography or by demonstrating flow voids or characteristic signal changes of hemorrhage using magnetic resonance imaging [51].

Carcinomatous meningitis occurs in approximately $5 \%$ of cancer patients at autopsy $[52,53]$. Intradural extramedullary or intramedullary metastases have frequencies of less than $4 \%$ that of epidural spinal cord compression [54]. Noncompressive causes of neural involvement should also be considered. Vascular damage to the spinal cord may cause myelopathy as a result of direct pressure or compression of major feeding radicular arteries as they enter through the intervertebral foramina. Myelopathy secondary to radiation, intrathecal methotrexate chemotherapy, infectious diseases, coagulopathies and paraneoplastic syndromes may occur in patients with cancer $[10,40]$.

\section{Clinical prognosis}

The severity of weakness at presentation is the most significant prognostic variable for recovery of function. Eighty percent of patients who were ambulatory at presentation, remain so after treatment [2].
Between $30-45 \%$ of patients who are nonambulatory with antigravity proximal leg function will regain ambulation, where as only $5 \%$ of patients who have no antigravity proximal function will walk again [2]. (Helweg-Larson S, Sorenson PS, Hanson $\mathrm{SW}$, personal communication). The radiobiology of the tumor also plays an important role in response. In one study, $75 \%$ of patients with radiosensitive tumors, who were nonambulatory but could raise their legs off the bed became ambulant after radiotherapy, but only $34 \%$ of comparable patients with radioresistant tumors became ambulant after radiotherapy [2]. After treatment, the probability of ambulant patients surviving one year is 0.73 and the probability of non ambulant patients surviving one year is 0.09 [55]. In selected series of paraplegic patients with anterior epidural spinal cord compression treated with anterior decompression and radiotherapy, between $50-90 \%$ of patients had an improvement in motor function $[24,56]$.

Histology of the tumor may be more important in determining prognosis than the type of treatment [1]. Myeloma, lymphoma and breast carcinoma have almost a $80 \%$ initial response rate and $75 \%$ of patients with breast carcinoma who are still alive at a year remain ambulatory $[2,28]$. Only $25 \%$ of patients with lung or renal carcinoma and melanoma respond to any treatment modality [2].

Rapid onset and quick progression are bad prognostic variables [57]. Patients with a pre-operative symptom duration greater than 2 months have better postoperative recovery of function than those with shorter histories [58]. The duration of paraplegia before starting treatment is also important. It has been traditionally taught that when paraplegia is present for greater than 24 hours before initiation of treatment the changes of recovery are slight [59, $60]$, although recent reports question this doctrine [61].

\section{Investigations}

Plain $\mathrm{x}$-rays are an essential, highly predictive, inexpensive, quick investigation that should be obtained if myelography or magnetic resonance imaging scanning is pending. Between $85-94 \%$ of pa- 
tients with metastatic epidural spinal cord compression have an abnormal plain $\mathrm{x}$-ray at the time of presentation [26]. If there is back pain or a localizing sign and spinal $x$-ray is abnormal, the probability of epidural disease is 0.9 , but if the $\mathrm{x}$-ray is normal, it is only $0.1[16,62]$. Spinal $x$-rays have a sensitivity of $91 \%$ for predicting epidural disease and a specificity of $86 \%$ [62]. Bone scanning has a similar sensitivity but a specificity of only $53 \%$. Particularly useful radiological features for predicting epidural disease are; greater than $50 \%$ vertebral collapse $(85 \%)$, and pedicular erosion $(31 \%)[14,62]$.

Spinal computed assisted tomography is valuable in investigating cancer patients with local back pain who have a normal exam and spinal x-rays. Two thirds of these patients have spinal metastases on computer assisted tomography scan but only $17 \%$ will have metastatic epidural spinal cord compression and in these cases none will have greater than $50 \%$ block [13]. Patients without cortical disruption on computer assisted tomography, rarely develop metastatic epidural spinal cord compression at that site at a later date [63].

Different algorithms for the investigation of patients with cancer and back pain have resulted from recent clinical studies utilizing spinal $x$-rays, bone scanning and spinal computed assisted tomography $[15,16,62]$. All advise myelography, with or without computed assisted tomography, if the spinal $x$-ray is abnormal (Table 1, authors algorithm).

Magnetic resonance imaging is replacing myelography as the procedure of choice, although there are no prospective trials comparing the diagnostic yield of myelography, with or without spinal computer assisted tomography, with that or magnetic resonance imaging in patients presenting with symptoms suggestive of metastatic epidural spinal cord compression $[64,65]$. However, it is adviseable to get the test that is readily available, as the patient may deteriorate while waiting for investigation. In many centers this may still be myelography with or without computer assisted tomography.

Magnetic resonance imaging is non-invasive, effectively demonstrates metastatic epidural spinal cord compression and gives a positive image of the spinal cord to better diagnose intramedullary disease [64-66]. Intradural extramedullary metastases
[12] are equally well diagnosed by gadolinium enhanced magnetic resonance imaging or by myelography $[64,66]$. Asymptomatic second areas of metastatic epidural spinal cord compression are identified with MRI and are important for radiation planning. Anatomical definition of vertebral and extraspinal disease on magnetic resonance imaging is helpful when planning a surgical procedure. It is helpful to perform sagittal magnetic resonance imaging 'scout scans' (Fig. 1), using the body coil, as they will often identify multiple vertebral deposits which can subsequently be studied in more detail using local spinal coils (Fig. 2). Magnetic resonance imaging has fewer risks than myelography in patients with intracranial mass lesions or bleeding tendencies. Where there has been previous surgery or scoliosis, sagittal images are difficult to interpret. Patients who are claustrophobic or who have a ferromagnetic implant cannot be scanned. Severe pain or other causes of movement artifact may limit interpretation of the scans and myelography would then be preferable.

Myelography is as sensitive as magnetic resonance imaging at identifying extradural or intradural extramedullary lesions and has the added advantage of yielding cerebrospinal fluid which may help to exclude or confirm alternative diagnoses, e.g. carcinomatous meningitis or abscess. The addition of spinal computer assisted tomography improves sensitivity for bony and paravertebral involvement. Clinical deterioration may occur directly following myelography $[67,68]$, however, it is difficult to separate this from natural history of disease. If there is a complete block following lumbar injection, a cervical myelogram or magnetic resonance imaging is necessary to visualize the upper limit of the block and to exclude second lesions. All patients with suspected MESCC should have their total spine imaged [69].

If the cause of epidural spinal cord compression is uncertain, computer assisted tomography guided biopsy of a paraspinal or epidural mass or percutaneous needle biopsy of a collapsed vertebral body may be helpful [70].

Simple investigations such as chest radiograph, prostatic specific antigen, mammography, abdominal ultrasound or abdominal and chest computer 


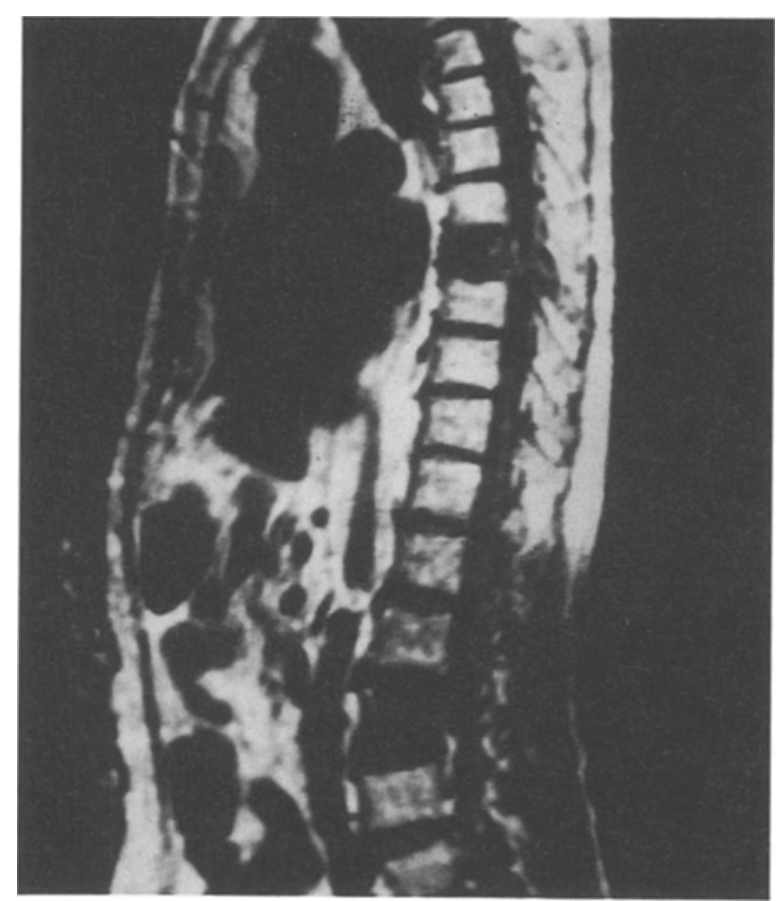

Fig. 1. MRI (using the body coil) showing two areas of vertebral involvement. One with ESCC at T8 and another asymptomatic L3 metastasis.

assisted tomography scan may immediately demonstrate the primary malignancy in patients who present with metastatic epidural spinal cord compression.

\section{Treatment recommendations for patients at risk from metastatic epidural spinal cord compression}

In order to improve clinical outcome in the future, it is important to identify patients at high risk for metastatic epidural spinal cord compression, before the appearance of neurological symptoms of signs. Patients with malignancy should be advised to inform their physician if they develop new back pain, the initial complaint in up to $96 \%$ of patients who go on to develop metastatic epidural spinal cord compression. High risk patients will include patients with known malignancy and recent onset back pain and patients who are not known to have malignancy, but who have new backache, worse on recumbency or radicular, situated in the thoracic region or associated with spinal tenderness. These pa-

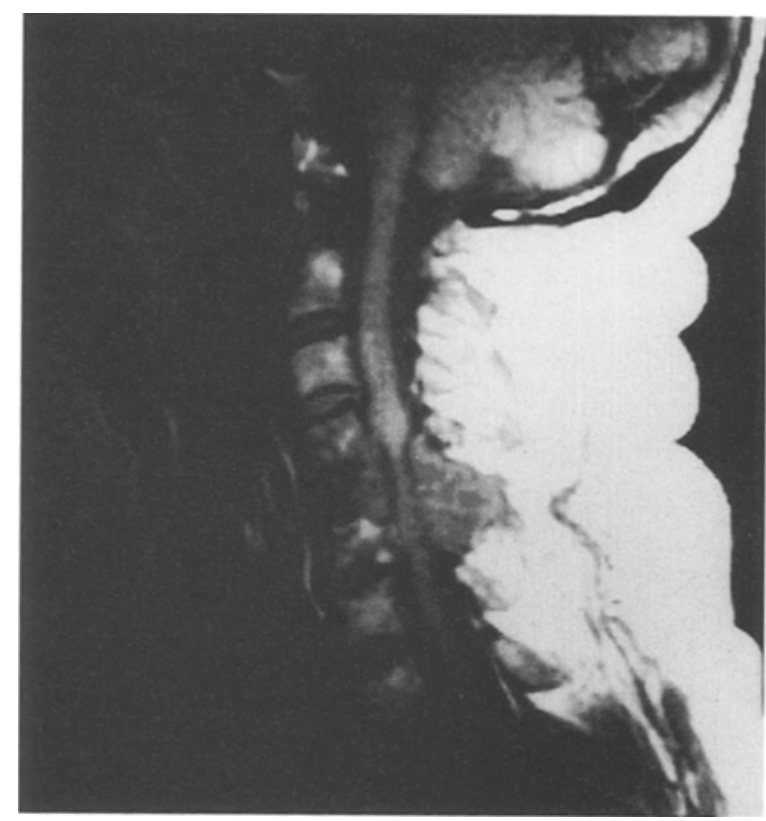

Fig. 2. MRI (using local spinal coil) showing severe metastatic ESCC with collapse of C5 vertebral body and severe destruction of posterior elements and local invasion of $\mathrm{C} 4$ and $\mathrm{C} 6$ bodies.

tients will require A-P and lateral plain x-rays of the involved areas (Table 1 ). Oblique $\mathrm{x}$-rays are needed if there is radicular pain as foramina enlargement may be missed on standard views. If there is evidence of focal bony pathology, myelography will demonstrate an abnormality in approximately $60 \%$ of cases [44]. If the spine $x$-rays are normal but the pain is characteristic, a spinal computer assisted tomographic scan is recommended [13], since plain xrays have a false negative rate of up to $17 \%$ [71]. Spinal computer assisted tomographic scanning will accurately differentiate between bony metastases and benign bony disease [63]. If computer assisted tomography demonstrates bony metastases or a paraspinal mass, then MRI or computer assisted tomography-myelography is indicated.

Radiation therapy is the treatment of choice for bony metastases without metastatic epidural spinal cord compression, as this provides very effective palliation for bone pain and will prevent progression to epidural metastases in most cases [72]. 
Table 1.

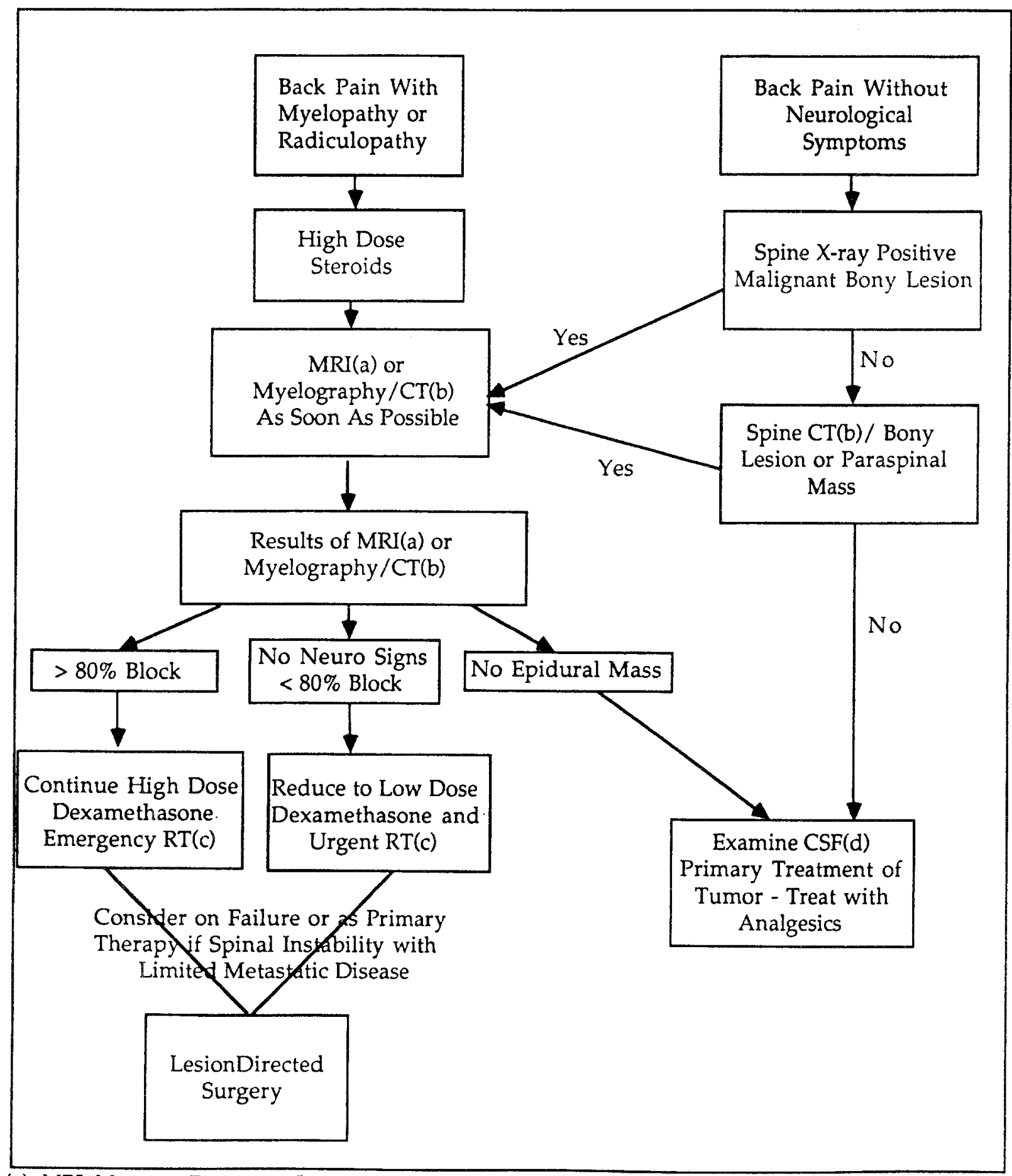
(a) MRI: Magnetic Resonance Imaging
(d) CSF: Cerebrospinal Fluid
(b) CT: Computed Tomography
(c) RT: Radiation Therapy 


\section{Emergency measures}

Patients with cancer, back pain and an abnormal progressing neurologic examination, demonstrating myelopathy or radiculopathy, should undergo emergency MRI or computer assisted tomographymyelography, whichever is the most readily available procedure (Table 1). Stable patients with uncertain neurological findings can be scanned urgently over the next twenty-four hours. Control of pain prior to myelography or magnetic resonance imaging may help to prevent movement artifact. High doses of steroids such as $100 \mathrm{mg}$ dexamethasone i.v. and $24 \mathrm{mg}$ six hourly will produce pain relief in $64 \%$ of patients within 24 hours and can also result in significant clinical improvement [28]. High dose i.v. dexamethasone can cause side effects including vaginal burning, elevations in blood pressure and glucose intolerance and electrolyte disturbance, and caution should be used in those suspected of having an infection or gastrointestinal symptoms. Doses should be tapered rapidly and immediately if there is less than $80 \%$ spinal block or gradually after 72 hours, following treatment with radiotherapy or surgery.

Patients with MESCC and abnormal neurologic examination with weakness should be monitored at frequent intervals with a neurologic exam. If patients develop a neurologic deficit during radiation therapy and it is unresponsive to steroid dose increase, directed surgical approach should be considered. If back pain is due to vertebral involvement with spinal instability and the patient has otherwise limited disease spinal stabilization should be considered [73].

In experimental studies, dexamethasone can be identified in spinal cord within 5 minutes of i.v. injection and has a half life of approximately 4 hours. A dexamethasone dose response effect has been demonstrated in an animal model of metastatic epidural spinal cord compression $[7,38]$, producing decreased spinal cord water content, reduced epidural swelling and a transient clinical improvement. A prospective randomized double blinded trial of single high dexamethasone dose (100 $\mathrm{mg}$ iv) compared with conventional initial dose ( $10 \mathrm{mg}$ iv), both subsequently followed by 4 mg orally every 6 hours did not demonstrate a significant difference in ambulation, bladder function or control of pain at 24 hours [74]. However at 3 hours, 7\% of patients treated with the conventional initial dose steroids deteriorated and only $41 \%$ had pain relief, compared with no deterioration and $53 \%$ pain relief in the high initial dose group. Based on the half life of dexamethasone any effect of single high dose decadron would be expected to be of short duration and a more prolonged course of high dose steroids may be justified. In a prospective randomized double blind placebo controlled trial in acute spinal cord injury, high dose bolus and then continuous methylprednisone improved neurologic motor and sensory recovery [75].

Patients with neoplastic spinal cord compression are at an increased risk of deep venous thrombosis and pulmonary embolus. Prophylactic subcutaneous heparin, anti-embolic stockings or compression pumps [76], will help reduce morbidity and mortality. In the presence of urinary retention or constipation, intermittent or permanent catheterization should be considered and laxatives/suppositories should be initiated early in the course of admission. Care should be taken when nursing patients with paraparesis or paraplegia to prevent pressure sores. In patients who have previously been treated with maximal radiation therapy and who are unfit for surgery, non operative treatment with spinal braces can be offered.

From 1963-1980 several selected series [30, 33, 37] compared the results of surgical decompression alone versus decompression followed by radiation therapy and demonstrated markedly better results in the latter group. In 1978, a retrospective non-randomized series of 235 patients with metastatic epidural spinal cord compression concluded that radiation therapy alone is as effective as decompressive laminectomy and radiation therapy [2]. This study was instrumental in changing initial therapy for metastatic epidural spinal cord compression from surgery to radiation therapy. There has only been one randomized prospective comparison of laminectomy followed by radiation therapy versus radiation therapy alone [78]. This failed to reveal any difference between the treatment arms, however the sample size made it difficult to demonstrate a significant difference $[29,78]$. Recently, a renewed 
interest in surgery has focused on a directed surgical approach based on the site and level of metastatic epidural spinal cord compression.

\section{Radiotherapy}

The response of epidural metastatic lesions to radiation is well documented [27, 79-81]. Lymphoma, seminoma, myeloma, Ewing's sarcoma and neuroblastomas are very radiosensitive, breast and prostate less so, and kidney, colon, lung and melanoma are frequently radioresistant.

Radiation therapy is still the generally accepted first line of treatment of metastatic epidural spinal cord compression in radiosensitive tumors. Its use in radioresistant tumors is more controversial. A large retrospective study reported that radioresistant tumors are as effectively treated with radiation therapy alone as with laminectomy and radiation therapy [2]. The optimal dose and fractionation regimen for metastatic epidural spinal cord compression remains unknown [82]. In fact, there may be no generally optimal plan. Each plan constructed represents a compromise between delivery of the highest dose achievable to improve tumor control, a desire to achieve palliation as expediently as possible, and the intrinsic radiosensitivity of the spinal cord, often a regimen of $30 \mathrm{~Gy}$ in 10 fractions is chosen as the best solution [82].

The treatment technique depends upon the region of spinal involvement. Cervical spine lesions are generally treated with opposed lateral portals that provide a homogenous dose distribution to the involved region while sparing the pharyngeal mucosa from the acute effects of radiation. Thoracic spine lesions are most often treated with posterior fields for simplicity and ease of patient setup. The additional dose delivered to more superficial tissues with a posterior-only beam arrangement can be significant especially for lower energy treatment units. A posterior wedged-pair arrangement minimizes this problem and also spares anteriorly situated soft tissues. Due to the near-midline location of the lumbar spine, these lesions are usually treated with opposed anterior and posterior portals. Traditionally, two vertebral bodies above and below the myelographic block have been treated, taking into account other vertebral bodies with documented metastasis. Whether these volume recommendations for spinal irradiation will continue in the modern imaging era remains to be seen. The sensitivity of the spinal cord to radiation limits the prescribed amount of therapy and the spinal cord dose should always be calculated as well as the dose to the involved vertebral body. The incidence of permanent radiation injury to the spinal cord directly correlates with the total dose and fraction size [83]. Spinal cord tolerance has been considered to be between 45-50 Gy in 180 cGy fractions, between 3537.5 Gy in 250 cGy fractions and between $30-33$ Gy in $300 \mathrm{cGy}$ fractions. In primates given a total radiation dose of $52 \mathrm{~Gy}$ in $2.2 \mathrm{~Gy}$ fractions, only $0.1 \%$ developed myelopathy with a latent period ranging from 5 to 20 months [84]. The size of the radiation field also plays an important role and reductions in treatment volume allow a larger dose [85]. Radiation therapy has recently been reported to produce a delayed recovery in ambulation ( 3 to 6 months) in patients paraplegic for up to nine days. Recovery was more common in patients whose weakness had a gradual onset over weeks [61].

\section{Surgery}

The role of surgery is being re-evaluated. Surgery is a major undertaking in patients with metastatic disease who have limited life expectancy. Nevertheless, it has been advocated to obtain diagnostic material, to help the rapidly deteriorating patients, to decompress the spinal cord and nerve roots, correct spinal instability, relieve pain and promote early mobilization. Spinal instability is a potential cause of cord damage and is not affected by radiation therapy [25]. Recently, spinal surgeons extrapolating from traumatic spinal cord injury, and using a similar framework have divided the bony space into three columns: Anterior Column - anterior longitudinal ligament and vertebral body; Middle Column - posterior longitudinal ligament, posterior vertebral body, pedicles; Posterior Column - facet joints, lamina, interspinous ligaments. Spinal instability occurs most often if the cortical bone in more than 
one of three columns are involved, either by tumor or by previous surgery. Surgical relief of pain can be achieved in $68 \%$ to $85 \%$ of patients [20,21].

Most old trials compared decompressive laminectomy with radiation therapy. Decompressive laminectomy for metastatic epidural spinal cord compression in the presence of vertebral body collapse is contraindicated. It has a $25 \%$ risk of major neurological deterioration, $22 \%$ risk of spinal instability and only $3 \%$ recovery of ambulation $[56,86]$. The only indications for decompressive laminectomy are tissue diagnosis and removal of posteriorly situated epidural deposits, when vertebral disease is absent. In a retrospective study of patients with rapidly progressing weakness developing over 48 hours or less, radiation therapy was shown to be superior to posterior decompressive laminectomy in return of patients to ambulatory status [2]. In this same series radiosensitive lesions did better than radioresistant lesions regardless of treatment (surgery or radiation) emphasizing that the type of tumor is prognostically more important than the type of therapy [2]. Paraplegic patients traditionally have not improved with posterior decompressive laminectomy but anterior vertebral body resection shows some promise in paraplegic patients $[24,25]$. In surgically treated posterior metastatic epidural spinal cord compression, one-third of patients regain ambulation and continence, but the incidence of paraplegia increases from $8 \%$ pre-operatively to $26 \%$ post-operatively [23]. Problems with wound closure and infection, which may be increased with radiation therapy, produce significant morbidity. Longer term problems are spinal instability or nonfusion and worsening pain. Posterior stabilization may be required following decompressive laminectomy to prevent spinal instability.

In selected patients with spinal instability, anterior decompression should be considered before radiation therapy [73]. Patients with vertebral compression with anteriorly placed epidural lesions will require a transthoracic, transabdominal or retroperitoneal approach for vertebral body resection. Anterior stabilization is usually produced using Steinmann pins and methyl methacrylate or bone graft. Concomitant posterior stabilization may be necessary if the neural arch is also involved with tumor.
Clinical outcome following anterior decompression in patients with a single anteriorly situated epidural metastasis is remarkably good. Fifty-two percent of these patients, who are in good general health and have either failed radiation or have a radioresistant tumor, will have an improvement in ambulation and a median survival of 16 months [24]. Operative mortality is $7 \%$ and surgical morbidity is $11 \%$. Transient neurological worsening occurs in approximately $2 \%$. Spinal instability develops in $5 \%$ of patients and recompression at the initial site will eventually occur in $22 \%$ of patients.

In other surgical series the vertebral body resection, pain improved in 60 to $97 \%$ and neurologic function improved in 55 to $97 \%[19,22,25,87]$. However, in one study the post-operative mortality was almost $36 \%$ [22]. In a small series of thirteen patients who had anterior decompression after failure of decompressive laminectomy, almost $50 \%$ deteriorate and only $8 \%$ improve [56]. Prior radiation therapy may also increase the morbidity and mortality of anterior decompression [25, 88].

Single stage synchronous anterior decompression by a posteriolateral approach with posterior stabilization has been advocated in patients with vertebral collapse and destruction of the neural arch posteriorly $[20,23]$. Initial results in selected patients are encouraging with two-thirds of nonambulant patients in one series regaining the ability to walk [20]. This combined procedure by a posteriolateral approach may reduce respiratory or abdominal complications related to anterior transthoracic or transabdominal surgery.

\section{Chemotherapy}

Chemotherapy may have a place in treating patients who have metastatic epidural spinal cord compression and have previously had radiation and are not surgical candidates, or those with widespread metastases [89-91]. Complete resolution of paraparesis following intravenous chemotherapy has been reported in patients with breast cancer who have failed radiation [92]. 


\section{Conclusion}

Epidural spinal cord compression is a complication of systemic malignancy and usually signifies disseminated disease with shortened survival. Early diagnosis is crucial. The initial symptom is almost always local back or radicular pain. If radiculopathy or myelopathy is present on neurological exam, or spine $\mathrm{x}$-rays are abnormal, emergent magnetic resonance imaging or myelography/computer assisted tomography is indicated. In cancer patients with local back pain and normal neurologic exam and spine $\mathrm{x}$-rays, the probability of metastatic epidural spinal cord compression is 0.1 and computer assisted tomography or magnetic resonance imaging scanning is recommended. If computer assisted tomography of the spine demonstrates cortical disruption, the patient should then have MRI or myelography. If investigations demonstrate a benign cause for backache this can be treated symptomatically. If investigations fail to reveal a clear cause for backache and symptoms presist, MRI and cerebral spinal fluid analysis for cytology is justified.

Proper emergent management of metastatic epidural spinal cord compression requires the close and timely cooperation of medical oncologists, radiologists, neurologists, neurosurgeons, orthopaedic surgeons and radiation oncologists. Steroids will reduce pain and may lead to temporary neurological improvement. Radiation therapy is equal in effect to posterior decompressive laminectomy in both radiosensitive and radioresistant tumors. Therefore, radiation is the most appropriate and readily available option for the majority of patients. In selected cases with anterior epidural compression and spinal instability, initial management should be an anterior surgical approach or synchronous vertebral decompression with posterior stabilization. Posterior decompressive laminectomy alone is contraindicated in patients with vertebral collapse. In patients with posterior epidural disease without tissue diagnosis, laminectomy with or without stabilization should be performed.

The literature on metastatic epidural spinal cord compression is notable for the lack of good randomized studies dealing with clinical aspects and therapeutic options. There is however, a randomized multi-institutional study in progress to investigate patients with metastatic epidural spinal cord compression who are 'surgical candidates' to study the question whether lesion directed surgery with stabilization and radiation is more effective than radiation alone.

\section{Acknowledgements}

The authors wish to thank Kathy Jones and Carol Cribbins for their expert secretarial assistance.

\section{References}

1. Barron KD, Hirano A, Araki S, Terry RD: Experiences with metastatic neoplasms involving the spinal cord. Neurology 9: 91-106, 1959

2. Gilbert RW, Kim JH, Posner JB: Epidural spinal cord compression from metastatic tumor: Diagnosis and treatment. Ann Neurol 3: 40-51, 1978

3. Arguello F, Baggs RB, Duerst RE, Johnstone L, McQueen K, Frantz CN: Pathogenesis of vertebral metastasis and epidural spinal cord compression. Cancer 65: 98-106, 1990

4. Arguello F, Baggs RB, Frantz CN: A murine model of experimental metastasis to bone and bone marrow. Cancer Res 48: 681-6881, 1988

5. Berretoni BA, Carter JR: Mechanisms of cancer metastasis to bone. J Bone Joint Surg 68: 308-312, 1986

6. Delattre JY, Arbit E, Rosenblum MK, Thaler HT, Lau N, Galicich JH, Posner JB: High dose versus low dose dexamethasone in experimental epidural spinal cord compression. Neurosurgery 22: 1005-1007, 1988

7. Delattre JY, Arbit E, Thaler HT, Rosenblum MK, Posner JB: A dose response study of dexamethasone in a model of spinal cord compression caused by epidural tumor. J Neurosurg 70: 920-925, 1989

8. Siegal T, Siegal TZ, Shapira Y, Sandbank U, Catane R: Indomethacin and dexamethasone treatment in experimental neoplastic spinal cord compression. Part 1: Effect on water and specific gravity. Neurosurgery 22: 328 -333, 1988

9. Strobel ES, Strobel HG, Bross KJ, Winterhalter B, Fiebig HH, Schlidge JU, Löhr GW: Effects of human bone marrow stroma on the growth of human tumor cells. Cancer Res 49: 1001-1007, 1989

10. Choucair AK: Myelopathies in the cancer patient. Oncology 5: 71-79, 1991

11. Coleman LK, Porter BA, Redmond J, Olson DO, Stimac GK, Dunning DM, Friedl KE: Early diagnosis of spinal metastasis by CT and MR studies. J Comput Assist Tomogr 12 (3): 423-426, 1988

12. Hagenau C, Grosh W, Currie M, Wiley R: Comparison of 
spinal magnetic resonance imaging and myelography in cancer patients. J Clin Oncol 5: 1663-1669, 1987

13. O'Rourke T, George CB, Redmond J, Davidson H, Cornett P, Fill WL, Spring DB, Sobel D, Dabe IB, Karl RD, Cromwell LD: Spinal computed tomography and computed tomographic metrizamide myelography in the early diagnosis of metastatic disease. J Clin Oncol 4: 51-583, 1986

14. Portnoy RK, Lipton RB, Foley KM: Back pain in the cancer patient: An algorithm for evaluation and management. Neurology 37: 134-138, 1987

15. Redmond J, Friedl KE, Cornett P, Stone M, O'Rourke T, George CB: Clinical usefulness of an algorithm for the early diagnosis of spinal metastatic disease. J Clin Oncol 6: 154 157,1988

16. Rodichok LD, Harper GR, Ruckdeschel JC, Price A, Roberson $\mathrm{G}$, Barron KD, Horton J: Early diagnosis of spinal epidural metastases. Am J Med 70: 1181-1188, 1981

17. Weisman DE, Gilbert M, Wang H, Grossman SA: The use of computed tomography of the spine to identify patients at high risk for epidural metastases. J Clin Oncol 3: 1541-1544, 1985

18. Cybulski GR: Methods of surgical stabilization for metastatic disease of the spine. Neurosurgery 25(2): 240-252, 1989

19. Findlay GFG: The role of vertebral body collapse in the management of malignant spinal cord compression. J Neurol Neurosurg Psychiat 50: 151-154, 1987

20. Johnston FG, Uttley D, Marsh HT: Synchronous vertebral decompression and posterior stabilization of spinal malignancy. Neurosurgery 25: 872-881, 1989

21. Kostuik JP, Errico TG, Gleason TF, Errico CC: Spinal stabilization of vertebral column tumors. Spine 13-250-256,1988

22. Moore AJ, Uttley D: Anterior decompression and stabilization of the spine in malignant disease. Neurosurgery 24: 713717,1989

23. Shaw B, Mansfield FL, Borges L: One stage posterolateral decompression and stabilization for primary and metastatic vertebral tumors in the thoracic and lumbar spine. J Neurosurg 70: 405-410, 1989

24. Siegal T, Siegal TZ: Surgical decompression of anterior and posterior malignant epidural tumors compressing the spinal cord: A prospective study. Neurosurgery 17: 424-432, 1985

25. Sundaresan N, Galicich JH, Lane JM, Bains MS, McCormack P: Treatment of neoplastic epidural cord compression by vertebral body resection and stabilization. J Neurosurg 63: 676-684, 1985

26. Stark RJ, Henson RA, Evans SJW: Spinal metastasis: A retrospective survey from a general hospital. Brain 105: 189213,1982

27. Constans JP, DeDivitis E, Donzelli R, Spaziante R, Meder $J F$, Haye C: Spinal metastases with neurological manifestations: Review of 600 cases. J Neurosurg 59: 111-118, 1983

28. Greenberg HS, Kim JH, Posner JB: Epidural spinal cord compression from metastatic tumors: Results with a new treatment protocol. Ann Neurol 8: 361-366, 1980

29. Sorenson PS, Borgesen SE, Rohide K, Rasmusson B, Bach
F, Boge-Rasmussen T, Stjernholm P, Larsen BH, Agerlin N, Gjerris F: Metastatic epidural spinal cord compression: Results of treatment and survival. Cancer 65: 1502-1508, 1990

30. White WA, Patterson RH, Bergland RM: Role of surgery in the treatment of spinal cord compression by metastatic neoplasm. Cancer 27: 558-561, 1971

31. Haddad P, Thaell JF, Kiely JM, Harrison EG, Miller RH: Lymphoma of the spinal extradural space. Cancer 38: 18621866,1976

32. Torma T: Malignant tumors of the spine and the spinal epidural space. Acta Clin Scand 225: 1, 1957

33. Wright RL: Malignant tumors in the spinal epidural space: Results of surgical treatment. Ann Surg 157: 227-231, 1963

34. Coleman DR, Delong RP: The role of the vertebral venous system in metastases of cancer to the spinal column: Experiments with tumor-cell suspension in rats and rabbits. Cancer 4: $610-618,1951$

35. Doppman JL: The mechanism of ischaemia in anteroposterior compression of the spinal cord. Investigative Radiology 10: $543-551,1975$

36. Gledhill RF, Harrison BM, McDonald WI: Demyelination and remyelination after acute spinal cord compression. Exp Neurol 38: 472-487, 1973

37. Rubin P: Extradural spinal cord compression by tumors. Part I: Experimental production and treatment trials. Part II: High daily dose experience without laminectomy. Radiology 93: 1243-1260, 1969

38. Ushio Y, Posner R, Posner JB, Shapiro WR: Experimental spinal cord compression by epidural neoplams. Neurology 27: 422-429, 1977

39. van der Sande JJ, Kroger R, Boogerd W: Multiple spinal epidural metastases: An unexpectedly frequent finding. J Neurol Neurosurg Psychiat 53: 1001-1003, 1990

40. Byrne TN, Waxman SG: Spinal cord compression: Diagnosis and principles of management. Contemporary Neurology Series. Philadelphia: F.A. Davis Company; 1990

41. Grossman SA, Lossignol D: Diagnosis and treatment of epidural metastasis. Oncology 4: 47-54, 1990

42. Ropper AH, Poskanzer DC: The progress of acute and subacute transverse myelopathy based on early signs and symptoms. Ann Neurol 4: 51-59, 1978

43. Bernat JL, Greenberg ER, Barrett J: Suspected epidural compression of the spinal cord and cauda equina by metastatic carcinoma. Clinical diagnosis and survival. Cancer 51: 1953-1957, 1983

44. Rodichok LD, Ruckdeschel JC, Harper GR, Cooper G, Prevosti L, Fernando L, Baxter DH: Early detection and treatment of spinal epidural metastases: The role of myelography. Ann Neurol 20: 696-702, 1986

45. Ruff RL, Dougherty JHJ: Complications of lumbar puncture followed by anticoagulation. Stroke 12: 879-881, 1981

46. Hughes WT, Armstrong D, Bodey GP, Feld R, Mandell GL, Myers JD, Pizzo PA, Schimpff SC, Shenep JL, Wade JC, Young LS, Yow MD: Guidelines for the use of antimicrobial agents in neutropenic patients with unexplained fever. J Infect Dis 161: 381-390, 1990 
47. Schimpff SC: Empiric antibiotic therapy for granulocytopenic cancer patients. Am J Med 80(Suppl 5C): 13-20, 1986

48. Haddad SF, Hitchon PW, Godersky JC: Idiopathic and glucocorticoid induced spinal epidural lipomatosis. J Neurosurg 74(1): 38-42, 1991

49. Baker AS, Ojemann RG, Swartz MN, Richardson EP: Spinal epidural abscess. NEJM 293: 463-468, 1975

50. Kaufman DM, Kaplan JG, Litman N: Infectious agents in spinal epidural abscesses. Neurology 30: 81-84, 1980

51. Terwy B, Becker H, Thran AK, Vahldiek G: GadoliniumDPTA enhanced MR imaging of spinal dural arteriovenous fistulas. J of Computer Assisted Tomography 13(1): 30-37, 1989

52. Hajdu SI, Ashton RP, Carter D, Lang WR, Sullivan M: Diagnostic cytology seminar. Acta Cytol 26: 851-852, 1982

53. Wasserstrom WR, Glass JP, Posner JB: Diagnosis and treatment of leptomeningeal metastases from solid tumors. Experience with 90 patients. Cancer 49: 759-772, 1982

54. Posner JB: Management of central nervous system metastases. Semin Oncol 4: 81-91, 1977

55. Ruff RL, Lanska DJ: Epidural metastases in prospectively evaluated veterans with cancer and back pain. Cancer 11: 2234-2241, 1989

56. Harrington KD: Anterior cord decompression and spinal stabilization for patients with metastatic lesions of the spine. J Neurosurg 61: 107-117, 1984

57. Brice J, McKissock W: Surgical treatment of malignant extradural spinal tumors. Br Med J 1: 1341-1346, 1965

58. Smith R: An evaluation of surgical treatment for spinal cord compression due to metastatic carcinoma. J Neurol Neurosurg Psychiat 28: 152-158, 1965

59. Black P: Spinal metastasis: Current status and recommended guidelines for management. Neurosurgery 5: 726-746, 1979

60. Tang SG, Byfield JE, Sharp TR, Utley JF, Quinol L, Seagren SL: Prognostic factors in the management of metastatic epidural spinal cord compression. J Neuro-Oncol 1: 21-28, 1983

61. Helweg-Larsen S, Rasmusson B, Spoelberg Sorenson P: Recovery of gait after radiotherapy in paralytic patients with metastatic epidural spinal cord compression. Neurology 40: 1234-1236, 1990

62. Portenoy RK, Galer BS, Salamon O, Freilich M, Finkel JE, Milstein D, Thaler HT, Berger M, Lipton RB: Identification of epidural neoplasms: Radiography and bone scantigraphy in the symptomatic and asymptomatic spine. Cancer 64: 2207-2213, 1989

63. Redmond J, Spring DB, Munderloh SH, George CB, Mansour RP, Volk SA: Spinal computed tomography scanning in the evaluation of metastatic disease. Cancer 54: 253-258, 1984

64. Godersky JC, Smoker WR, Knutson R: Use of magnetic resonance imaging in the evaluation of metastatic spinal disease. Neurosurgery 21: 61-680, 1987

65. Lien HH, Blomlie V, Heimdal K: Magnetic resonance imaging of malignant extradural tumors with acute spinal cord compression. Acta Radiol 31(2): 187-190, 1990
66. Stimac GK, Porter BA, Olson DO, Gerlach R, Genton M: Gadolinium - DTPA - enhanced MR imaging of spinal neoplasms: Preliminary investigation and comparison with unenhanced spin-echo and STIR sequences. AJR 151: 11851192, 1988

67. Eaton LM, Craig WM: Tumors of the spinal cord: Sudden paralysis following lumbar puncture. Proceedings of the Staff Meetings of the Mayo Clinic 15: 170-172, 1940

68. Hollis PH, Malis LI, Zappulla RA: Neurological deterioration after lumbar puncture below complete spinal subarachnoid block. J Neurosurg 64: 253-256, 1986

69. Bonner JA, Lichter AS: A caution about the use of MRI to diagnose spinal cord compression. NEJM 322: 556-557, 1990

70. Fyfe I, Henry A, Mulholland R: Closed vertebral biopsy. B J Bone Joint Surg 140-143, 1983

71. Fletcher JW, Solaric-George E, Henry RE, Donati RM: Radioisotopic detection of osseous metastases: Evaluation of $99 \mathrm{~m}$ Tc polyphosphate and $99 \mathrm{~m}$ Tc pyrophosphate. Arch Int Med 135(5): 553-557, 1975

72. Arcangeli G, Micheli A, Arcangeli G, Giannarelli D, La Pasta $\mathrm{O}$, Tollis A, Vitullo A, Ghera S, Benassi M: The responsiveness of bony metastases to radiotherapy: The effect of site, histology and radiation dose on pain relief. Radiotherapy and Oncology. Elsevier, New York 14: 95-101, 1989

73. Perrin RG, McBroom RJ: Spinal fixation after anterior decompression for symptomatic spinal metastasis. Neurosurgery $22: 324-327,1988$

74. Vecht ChJ, Haaxma-Reiche H, van Putten WLJ, de Visser $\mathrm{M}$, Vries EP, Twijnstra A: Initial bolus of conventional versus high dose dexamethasone in metastatic spinal cord compression. Neurology 39: 1255-1257, 1989

75. Bracken MB, Shepard MJ, Collins WF, Holford TR, Young W, Baskin DS, Eisenberg HM, Flamm E, Leo-Sumers L, Maroon J, Marshall LF, Perot PL, Piepmeier J, Sonntag VKH, Wagner FC, Wilberger JE, Winn HR: A randomized controlled trial of methylprednisone or Naloxone in the treatment of acute spinal cord injury. NEJM 322: 1405-1411, 1990

76. Allenby F, Boardman L, Pflug JJ, Calnan JS: Effects of external pneumatic intermittent compression on fibrinolysis in man. Lancet 22: 1412-1414, 1973

77. Wild WO, Porter RW: Metastatic epidural tumor of the spine. Arch Surg 87: 137-142, 1963

78. Young RF, Post EM, King GA: Treatment of spinal epidural metastases: Randomized prospective comparison of laminectomy and radiotherapy. J Neurosurg 53: 741-748, 1980

79. Brady LW, Antoniades J, Prasavinichai S, Torpie RJ, Asbell SO, Glassburn JR: The treatment of metastatic disease of the nervous system by radiation therapy. In: Seydel HH (ed) Tumors of the Nervous System. John Wiley and Sons, New York, 11-188, 1975

80. Martenson JA, Evans RG, Lie MR, Ilstrup DM, Dinapoli RP, Ebersold MJ, Earle JD: Treatment outcome and complications in patients treated for malignant epidural spinal cord compression. J Neuro Oncol 3: 77-84, 1985

81. Mones RJ, Dozier D, Bennett A: Analysis of medical treat- 
ment of malignant extradural spinal cord tumors. Cancer 19: 1842-1853, 1966

82. Wara WM, Phillips TL, Sheline GE, Schwade JG: Radiation tolerance of the spinal cord. Cancer 35: 1558-1562, 1975

83. McCuniff AJ, Liang MJ: Radiation tolerance of the cervical spinal cord. Int J Radiat Oncol Biol Phys 16: 675-678, 1989

84. Schultheiss TE: Spinal cord radiation tolerance: Doctrine versus data. Int J Radiat Oncol Biol Phys 19: 219-221, 1990

85. Tiver K: Treatment of CNS tumors with conventional radiotherapy: The importance of dose and volume factors in tumor control and CNS radiation tolerance. Austrailian Radiol 33: 15-22, 1989

86. Findlay GFG: Adverse effects of the management of malignant spinal cord compression. J Neurol Neurosurg Psychiat 47: 11-18, 1984

87. Sundaresan N, Galicich JH: Treatment of spinal metastases by vertebral body resection. Cancer Invest 2: 383-397, 1984

88. Levy WJ, Latchaw JP, Hardy RW, Hahn JB: Encouraging surgical results in walking patients with epidural metastases. Neurosurgery 11(2): 229-233, 1982

89. Murphy WT, Bilge N: Compression of the spinal cord in patients with malignant lymphoma. Radiology 82: 495-501, 1964

90. Posner JB, Howieson J, Cvitkovic E: Disappearing spinal cord compression: Oncolytic effect of glucocorticoids (and other chemotherapeutic agents) on epidural metastases. Ann Neurol 2: 409-413, 1977

91. Silverberg IJ, Jacobs EM: Treatment of spinal cord compression in Hodgkins disease. Cancer 27: 308-313, 1971

92. Boogerd W, van der Sande JJ, Kroger R, Bruning PF, Somers R: Effective systemic therapy for spinal epidural metastases from breast carcinoma. Eur J Cancer Clin Oncol 25(1): 149-152, 1989

Address for offprints: H.S. Greenberg, University of Michigan, Department of Neurology, 1500 E. Medical Center Drive, 1914 Taubman Center, Box 0316, Ann Arbor, MI 48109-0316, USA 